\title{
International Co-Authorship and Research Team Performance in Colombia
}

\author{
Gonzalo Ordóñez-Matamoros \\ Universidad Externado de Colombia \\ gonzalo.ordonez.co@gmail.com \\ Susan E. Cozzens \\ Georgia Institute of Technology \\ susan.cozzens@pubpolicy.gatech.edu \\ Margarita García-Luque \\ mgarcialuque@hotmail.com
}

\begin{abstract}
Recent trends show that Colombian S\&T performance is improving rapidly. This paper examines the ways in which International Scientific Collaboration, as observed by the co-authorship of journal articles written by local scientists and partners located overseas, affects the ability of research teams to produce bibliographic outputs and to contribute to local knowledge. A sample of 672 teams was randomly selected for the analyses. Research hypotheses were tested using Zero Inflated Negative Binomial Regression and Logistic regression, as well as through the use of control groups and the Propensity Score Matching approach to assess the overall impact of the scientific collaboration on research team performance. In addition, 20 interviews with experts and team members were administered to discuss models and results. Results show that co-authoring with partners located overseas increases team output by nearly $40 \%$ and by between 3 and 5 bibliographic products. It also shows that team's odds of involving Colombia in its research process are 2.2 times larger for those co-authoring with a partner located overseas than for those that do not. Theoretical and policy implications are discussed!
\end{abstract}

\section{INTRODUCTION}

Colombia is what the Rand Corporation would call an S\&T-Developing Country: it has S\&T strength in few research areas but lacks important aspects of S\&T capacity in personnel, infrastructure, investment, and institutional framework [1].

However, recent trends show that Colombian scientific performance is improving rapidly. In 2001 there were 1,728 articles published by 126 Colombian journals. In 2007 this number almost tripled reaching almost 5,000 articles published in 222 local journals [2]. Furthermore, in 1990 there were 0.6 Colombian articles appearing in high quality journals reported by the Science Citation Index per 100,000 inhabitants. In 2006 there were 2.6; showing one of the largest growth rates in the region [3]. Finally, in 1995 there were 1.5 articles reported by the SCI per million dollars spent on R\&D. In 2006 there were 4.5 articles per million dollars.

Likewise, although the country continues to lag in the technological race, its technological capability is also improving relatively fast. According to the Colombian Observatory of Science and Technology, in 2001 there were 65 patent applications by Colombian residents; six years later there were 141 . While in 2001 there were 0.24 of such patents per 100000 population, in 2006 this number increased to 0.32 patents.

Probably more important is the fact that Colombia is becoming a more autonomous country from the knowledge produced overseas dealing with local issues. In fact, based on the analysis of the documents published between 1980 and 2005 in journals indexed by the ISI's Web of Knowledge, local scientists appeared to write relatively less about Colombian issues or use Colombia as their unit of analyses than scientists located overseas. As shown in Figure 1, Colombian S\&T seems to be barely self-sufficient (countries above the 0 level produce relatively more knowledge involving their country than scientist located overseas writing about this same country. Those located below the 0 level are said to be dependent on international STI capacity).

\footnotetext{
! This material is based upon work supported by the National Science Foundation under Grant Number 0647126. Any opinions, findings, and conclusions or recommendations expressed in this material are those of the author and do not necessarily reflect the views of the National Science Foundation. The Colombian Chapter of the Fulbright Commission provided additional funding for the participation of one of the authors in the Atlanta Conference.
} 


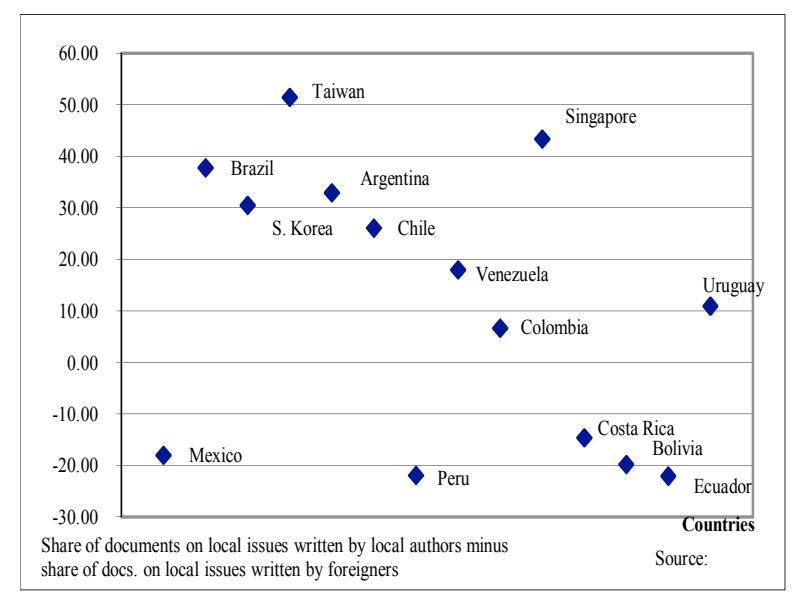

Fig. 1. Colombian contribution to local knowledge: Domestic versus foreign contributions: 1980-2005

However, this pattern has changed recently, showing a more local autonomous capacity. While in the 70s and 80s Colombia was mostly dependent of the knowledge produced overseas, since the 90 s the country became self-sufficient showing a trend evolving rapidly.

These developments are presumably the result of at least two 'mega trends' characterizing Colombian current S\&T system: 1) the rapid professionalization of the $R \& D$ enterprise as reflected by the formation of research teams with the support of the Colombian government and the elite research institutions; and 2) the internationalization of its scientific community, especially since the 1990s after the opening of the economy to foreign trade.

Hence, this paper examines these intertwining trends, and particularly the ways in which international research collaboration affects the performance of research teams both in terms of their productive capacity and of the orientation of their research agendas.

\section{Colombian S\&T Institutionalization and Internationalization processes}

As part of the policies led by Colciencias (the Colombian Science Foundation) and the Ministry of Education oriented at supporting the performance of R\&D activities in a more professional and formal way, the number of researchers affiliated to centers and 'teams' has boosted in the past decade. It rose from less than 5,000 in 1995 , to more than 12,000 in 2000 , to nearly 20,000 in 2005 . Today, these teams host most of the Colombian scientific community estimated by the OCyT to be of more than 50,000 individuals, of which more than 24,000 are researchers, of which more than 12,000 people report research outputs. Hence, more than $80 \%$ of the researchers reporting S\&T products is affiliated to a Research Team [2].

Similarly, Colombian S\&T internationalization is taking place at rapid pace. This is evident both in terms of its increased visibility (the number of articles appearing in international databases has dramatically increased although the participation of Colombian scientists in international forums remains relatively small) and in terms of the number of international scientists working in Colombia or with Colombian scientists and engineers [4]. In this sense, as revealed by the data from the Web of Knowledge on more than 5,400 journal articles published by Colombian scientists and engineers between 1980 and 2005, this recent good performance seems to be explained by the country's increased international collaboration. As shown in Figure 2, while the number of articles published by Colombians alone is rather small, that published in collaboration with foreign partners is large and increasing rapidly.

\section{RESEARCH QUESTIONS AND HYPOTHESES.}

The literature on the effects of research collaboration on research performance is extant and rising. Research collaboration is mostly portrayed as an important enabler of science and technology development. It is considered to be 'better' than individualistic research in several respects. In this sense, many argue that research collaboration has greater epistemic authority $[5,6]$; facilitates diffusion of information and ideas; increases access to new knowledge and research tools; and offers visibility and feedback [7-9].

Moreover, most of the literature on the topic claims that research collaboration is an important source of creativity [10-13], scientific productivity [8, 14-17] and helps the consolidation of research agendas and the expansion of research areas.

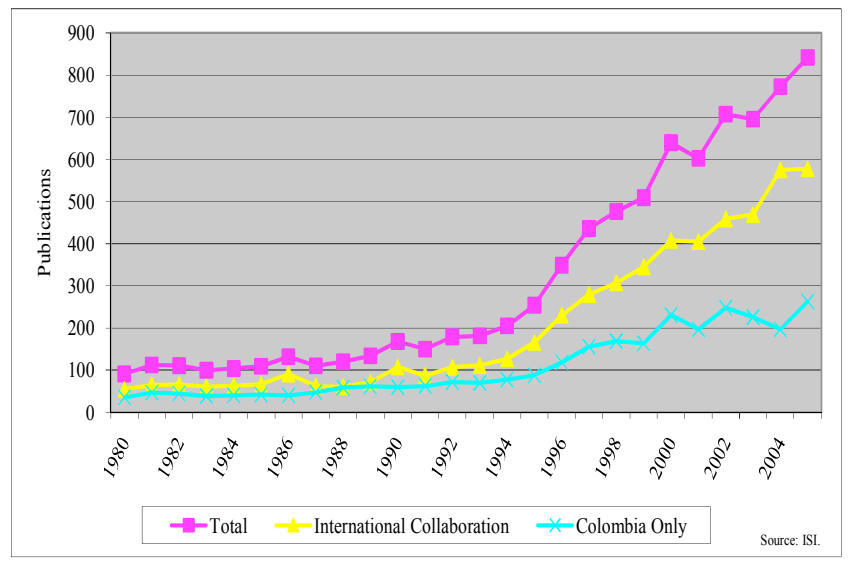

Fig. 2. Publications and research collaboration: total publications by Colombian scientists and engineers 1980-2005

Others, however, warn about the negative impacts of research collaboration on productivity [18-21] and relevance of the research [22-25]. Risks and costs identified include the privatization, capture and sometimes 'mercantilization' of traditional 'public' knowledge and of human capital as a result of research partnerships; increased secrecy; high opportunity costs and inefficient allocation of 
resources; and crowding out effects. A comprehensive literature review on the topic can be found in [4].

However, little is known about the effects of international collaboration on local S\&T capabilities, and the literature is astonishingly silent regarding the effects on both scientific productivity and research orientation involving developing countries. This paper examines the ways in which international scientific collaboration, as observed by the coauthorship of journal articles written by local scientists and partners located overseas, affects the ability of research teams to produce bibliographic outputs and to contribute to local knowledge in Colombia. More precisely, this paper addresses two questions: do Colombian teams that collaborate internationally are more productive than similar teams that do not? Do the collaborative teams work on $\mathrm{R}+\mathrm{D}$ projects and/or write journal articles that take into account Colombia either as unit of analysis, as 'laboratory,' or as the focus of their research activity more than non-collaborative teams?

Two research hypotheses can be drawn from these questions:

1) Co-authorship with partners located overseas positively affects team productivity. Given the lack of empirical research supporting this hypothesis, it is an extrapolation of the arguments found in the optimistic literature on research collaboration, which does not address international collaboration explicitly. In this sense, as in a collaborative enterprise everyone would offer something the other lacks and would get something would not be possible or easier to get otherwise, by collaborating with partners located in different milieus one can get a better understanding of one's own problems either by working together with researchers with different tools, perspectives and experiences or by studying one's partners' problems and/or solutions. By doing so, we complement our knowledge with that of our peers. In a sense, this is a variation to the "strength-of-weak-ties" argument proposed by Granovetter and Burt who claim that one has more to learn from those that see or have things one does not see or have, than from those of similar characteristics [11, 26, 27]. We call this the "complementarity" argument.

2) Co-authoring with partners located overseas negatively affects team's ability to contribute to local knowledge. Again, given the lack of empirical support to this hypothesis, one can extrapolate popular arguments found in the rather pessimistic literature on international relations (e.g. "dependency theory") which sees the partners of developing countries as "rent-seekers" willing to take advantage of the relatively low costs of qualified human resources despite the detours of this local capacity to engage in work on foreign interests. We call this the "outsourcing" argument.

\section{METHODOLOGY}

We rely on a dataset created with the information of 672 teams randomly selected from those registered at Colciencias ${ }^{1}$ with at least two members working together by 2003; at least one research project active between 2003 and 2005; teams not working in the social sciences or the humanities ${ }^{2}$, and teams created by March 2004. In addition, 20 interviews were administered with experts and team leaders working in several disciplines, affiliated to different types of institutions and located in four cities. The purpose of the interviews was to both to identify the control variables of relevance and to discuss the results obtained through the econometric models.

Two statistical approaches were followed to answer the research questions stated here: hypothesis testing using multiple regression models, and impact assessment using counterfactuals. Factors identified in the literature or thru expert opinion as determinants of team performance include: a) team size $[15,19,28-48]$; b) team age $[19,36,45,47,49$, $50]$; c) team composition $[49,51-54]$; d) experience $[55,56]$; e) leadership [57]; f) scientific specialization or discipline [14, 21, 32, 58-68]; g) sector where it works [14, 21, 69-72]; h) institution it is affiliated with [14, 21, 69-72], and i) its geographical location $[19,29,73-81]$.

Other variables found to affect team performance but that are usually hard to observe include $\mathbf{j}$ ) internal cohesion [39, 40, 49, 82]; k) institutional constraints; and l) government support [1,83-85].

Thus, a dummy variable was used to account for international co-authorship taking place in 2001 or 2002 based on the articles published by Colombian scientists and technicians in journals indexed by the Web of Science and Scopus ${ }^{3}$.

Team performance was measured by the number of bibliographic products (a category that includes 18 types of products $^{4}$ ) and by the extent to which the word "Colomb*" is used in the title of their research projects or journal articles,

\footnotetext{
${ }^{1}$ Colciencias, the Colombian National Science Foundation, maintains a directory of both individual researchers and research teams in two databases updated periodically following a process of calls for accreditation: CvLac and GrupLac respectively. These databases are freely available through the institution's website at www.colciencias.gov.co

${ }^{2}$ The reasons why the social sciences and the humanities were excluded are both practical and epistemological. Regarding the latter, it is commonly accepted that the main products of the teams working in these areas are not journal articles, but rather books. Since we are interested on the effects of co-authoring with colleagues located overseas on team productivity, focusing on journal articles would go against those teams. The practical reason is that, given the large number of researchers these teams usually have, the searching and assigning process would have been highly costly.

${ }^{3}$ This task was done with the aid of the Software VantagePoint developed at Georgia Tech and administered by Search Technology Inc.

${ }^{4}$ All the bibliographic products are given equal weight in the econometric analysis presented. Although this may be seen as problematic, the reason is that we are interested more on the scientific capacity of the teams to produce knowledge than on the quality or the relevance of their products themselves. The issue of relevance is analyzed differently here.
} 
or in their corresponding abstracts. The use of the keyword "Colomb*" is taken as a proxi of research orientation since references to a country usually result from scientific activities where the country is either the "milieu", the case studied, or a referent. In either case, relevant knowledge is derived, contributing therefore to the local stock of information necessary to increase local understanding and produce new knowledge valuable to solve local intellectual or social issues.

To avoid reverse causality and endogeneity, team performance was observed for the period 2003-2005, that is, three years after the collaborative activity took place.

As control variables we use team size (an interval-level variable for the number of researchers and technicians the team had in 2003); team age (an interval-level variable for how long the team had been in existence in 2003); the total number of $\mathrm{PhDs}$ (represented by an interval-level variable for the number of members with $\mathrm{PhD}$ degree the team had in 2003); team dynamism (measured by an interval-level variable for the number of $R \& D$ projects the team had active in 2003); scientific field (represented by six dummy variables, with teams working in the natural sciences as the reference group); sector (represented by three dummy variables, with teams working in the academic sector as the reference group); size of the home institution (represented by two dummy variables, with teams affiliated with big institutions as the reference group); and city-size (represented by two dummy variables, with teams located in big cities as the reference group).

A Zero-Inflated Negative Binomial (ZINB) model is used to account for the impact of international collaboration on team output. A Logistic Regression is used to account for the team's ability to contribute to local knowledge. And the Propensity Score Matching approach is used to construct the control groups and perform the counterfactual analysis to assess overall impact of international collaboration on both dependent variables studied.

The ZINB is used due to the fact that our first dependent variable analyzed is an account of the existence of sporadic team outputs typical of a count variable, as most research teams report zero or small number of products while few teams show large number of products in a given period, yielding a frequency distribution highly skewed to the left. According to reference [86], using the Linear Regression Model (LRM) - which is designed to fit a normal distribution resulting from a continuous-type of variables - to account for the effects of a given set of independent variables on a count dependent variable produces coefficients that are biased, inefficient and inconsistent. As the authors posit "even though there are situations in which the LRM provides reasonable results, it is much safer to use models specifically designed for count outcomes" [86]. Zero-inflated count models (ZIP and ZINB) respond to this issue and allow for the possibility of considering different causes of the unproductivity shown by the teams by increasing the conditional variance and the probability of zero counts. These models allow distinguishing between potentiallyproductive and always-unproductive teams ${ }^{5}$.

The Breusch-Pagan / Cook-Weisberg test was implemented to test for heteroskedasticity in the data. The test found that the 'constant variance of error term' assumption was violated. Although heteroskedasticity does not affect the parameter estimates as the coefficients are unbiased, it does bias the variance (and, thus, the standard errors) of the estimated parameters as the coefficients tend to be underestimated, therefore inflating z-scores and sometimes making insignificant variables appear to be statistically significant. To solve this problem, the Huber/White/sandwich estimator of variance is used in place of the traditional calculation. Therefore, the analyses are based on the robust estimation results.

A logistic regression is used to account for our second dependent variable as it is a dummy variable. As reference [87] notes, using Ordinary Least Square (OLS) regressions for dummy dependent variables, which by definition have either values of 1 or 0 , gives a linear probability model that violates the assumption of a normal distribution of the error term, and since the value of an independent variable changes, the variance of the error term for that variable would also change, leading to heteroskedasticity. In such case, the OLS estimators of the regression coefficients may be unbiased but cannot be efficient. Furthermore, estimates of the standard errors of the regression coefficients would be biased, distorting confidence intervals and hypothesis tests. Moreover, with OLS, the residuals would lead to meaningless expected probabilities such as negative probabilities since OLS assumes that the impact of marginal change of the value of an independent variable remains constant along all range of the values. In addition, according to reference [87], to use robust standard errors or weighted least squares "do not solve all the problems, such as probabilities outside the range between 0 and 1 , and therefore do not solve the conceptual problem of independent variables having constant impacts up to a certain point, then no impact beyond" [87]. If we use logit or probit we do not have these problems, since the impact of marginal change in the independent variable becomes increasingly non-linearly smaller as the probability gets closer to 0 or to 1 , yielding a probability distribution curve S-shaped ${ }^{6}$. In this paper a logit model is preferred over a

\footnotetext{
5 The analysis of the Poisson distribution of the team output as well as the process done to decide what model to use is shown in [4. Ordonez, G., International Research Collaboration, Research Team Performance, and Scientific and Technological Capabilities in Colombia -A Bottom-Up Perspective, in PhD Dissertation in Public Policy. Georgia Institute of Technology - Georgia State University. 2008: Atlanta, GA.

${ }^{6}$ The mathematical structure of binary models is not explored here, as a discussion on the statistical model will be out of scope of this paper. See Long, S. (1997) Regression Models for Categorical and Limited Dependent Variables. Thousand Oaks, CA: Sage Publications.
} 
probit model mostly due to personal preferences as there is no objective reason one would choose one versus the other.

The use of counterfactuals to assess overall impacts of international collaboration on team performance responds to the fact that the analyses intended imply two methodological challenges: selection bias and endogeneity of research collaboration. Selection bias results as there is no random 'assignment' of teams to the 'treatment' group. In practice, international partners might collaborate only with those teams and in those $R \& D$ projects that are expected to generate new knowledge and technologies. For this reason, the inclusion of research collaboration in a linear regression will cause endogenous effects, which would lead to inconsistent and biased estimates if it is correlated with the error term. To estimate the "real" effect of international research collaboration, it is therefore necessary to address the basic question: How would the teams with international research collaboration have performed had they not collaborated with international partners? To the authors' knowledge, no study on the impact of research collaboration, whether local or international, attempts to model this counterfactual situation. Most of the studies surveyed do not pay attention to this kind of bias (see a review in [4]). The only exception found is the study by Lee and Bozeman (2005), which analyzed the effect of research collaboration on the productivity of 443 academic scientists in the USA, and controlled for reverse causality by using a 2SLS using cosmopolitanism as the instrumental variable [16]. Their work does not consider counterfactuals and comparable control groups to assess impact, however.

The Propensity Score Matching (PSM) approach estimates causal "treatment" effects following reference [88]'s procedure ${ }^{7}$. In particular, we use the so-called balancing scores $b(X)$, that is, a function of the relevant observed covariates $X$ such that the conditional distribution given $b(X)$ is independent of 'assignment into a treatment' [89]. That balancing score is the Propensity Score: the probability of collaborating internationally given observed characteristics $X^{8}$. Reference [4] discusses the determinants of international research collaboration.

To contrast the productivity and probability of involving Colombia of a collaborating team with productivities and probabilities of comparison group teams, the kernel matching algorithm is used. Both a kernel function and a bandwidth parameter are used. To avoid the risk of using observations that are bad matches, the common support condition is imposed. To perform the analyses, the STATA module developed by Leuven and Sianesi (2003) is used to

\footnotetext{
${ }^{7}$ See detailed procedure in Ordonez, 2008 op.cit.

${ }^{8}$ The decision whether to apply PSM as opposed to Covariate Matching is not discussed here. See [90. Zhao, Z., Using Matching to Estimate Treatment Effects: Data Requirements, Matching Metrics, and Monte Carlo Evidence. The Review of Economics and Statistics, 2004. 80(1): p. 91-107. for Mahalanobis distance used to calculate similarity of two individuals in terms of covariate values, where the matching is done on these distances.
}

estimate the full model and test the balancing hypothesis using an iterative process to ensure that the estimated model is consistent with this requirement [91]. Since we do not condition on all covariates but on the propensity score, the matching procedure is checked to see if it is able to balance the distribution of the relevant variables in both the control and treatment group. This is done by comparing the situation before and after matching to see if there are any differences remaining after conditioning on the propensity score. Finally, the bootstrapping procedure is used to test the statistical significance of treatment effects and to compute their standard errors in case analytical estimates are biased or unavailable. Each bootstrap draw consisted in the reestimation of the results, including the estimation of propensity scores, common support, etc. The bootstrapping was repeated 999 times, which led to 999 bootstrap samples and 999 estimated average treatment effects.

\section{RESULTS}

Results show that international co-authorship is positively associated with team productivity. Particularly, it shows that co-authoring with partners located overseas increases team output by nearly $40 \%$, holding the other variables constant (see Table 1). This finding is statistically significant at the 0.01 level.

TABLE 1

Co-Authorship with Colleagues Located Overseas and Team Output

\begin{tabular}{|c|c|c|c|c|}
\hline & \multicolumn{2}{|c|}{$\begin{array}{c}\text { Tot. Bib. Prods. } \\
2003-5 \mathrm{a} \\
\end{array}$} & \multicolumn{2}{|c|}{ Always $0 \mathrm{~b}$} \\
\hline & $\%$ & $\mathrm{P}>|\mathrm{z}|$ & $\%$ & $\mathrm{P}>|\mathrm{z}|$ \\
\hline Co-Authorship in $2001-2$ & 39.2 & 0.011 & -2.3 & 0.992 \\
\hline Team size in 2003 & 4.0 & 0.013 & 14.8 & 0.553 \\
\hline Team Age in 2003 & 0.9 & 0.295 & -11.7 & 0.377 \\
\hline Total PhDs in 2003 & 7.5 & 0.015 & -49.9 & 0.531 \\
\hline Tot. Proj. in 2003 & 2.6 & 0.002 & -59.8 & 0.200 \\
\hline Agrosciences & 8.8 & 0.683 & 575.8 & 0.192 \\
\hline Medical Sciences & -16.4 & 0.209 & -85.6 & 0.774 \\
\hline Engineering & -1.3 & 0.916 & 44.5 & 0.754 \\
\hline Other Sciences & -23.7 & 0.164 & 1954.5 & 0.196 \\
\hline Business Sector & -54.2 & 0.031 & 1363.1 & 0.282 \\
\hline Government & 13.0 & 0.548 & 441.7 & 0.324 \\
\hline Other Sector & 55.4 & 0.199 & -100.0 & 0.001 \\
\hline Small Home Inst. & -21.1 & 0.215 & 6.4 & 0.944 \\
\hline Mid Home Inst. & 0.2 & 0.987 & -99.3 & 0.133 \\
\hline Small City & 65.8 & 0.121 & 5313.2 & 0.192 \\
\hline Midsize City & -6.9 & 0.563 & 3.6 & 0.967 \\
\hline In alpha & 0.28807 & & & \\
\hline alpha & 1.33385 & SE(alpha) & 0.14822 & \\
\hline
\end{tabular}


Furthermore, according to the data, co-authoring increases the expected productivity of teams by 2.91 bibliographic products, holding the other variables constant at their means (not shown in the table). However, co-authoring does not seem to be associated with the probability of being (or not being) in the unproductive group of teams.

Regarding the determinants of team productivity, and similar to the findings by Adams, Black et al., holding the other variables constant, team size appears to have positive effects on team output [15]. Number of $\mathrm{PhDs}$ and number of R\&D projects active also appear positively associated with team productivity. However, contrary to literature arguing positive effects of team age [45, 49], which is taken as a proxi for experience, it does not seem related to team productivity in this data.

Unsurprisingly, teams affiliated with the business sector appear less productive than teams affiliated with academic institutions, but belonging to a team affiliated with the business sector does not seem to affect the odds of being in the always- 0 group.

In this model, scientific field does not seem to be associated with team production and, interestingly, only the teams affiliated with the NGOs sector are significantly less likely than teams affiliated with academic institutions of being in the Always-0 group of unproductive teams.

No location effects were found and the size of the teams' host institution does not seem to matter as a predictor of team productivity.

To assess the overall effects of collaborating internationally using control groups following the PSM approach, co-authorship of articles with partners located overseas is taken as the treatments of interest. Table 2 summarizes the analyses done and shows the differences in productivity between collaborating and non-collaborating teams before and after the matching procedure. As the table shows, and consistent with the finding using the parametric model, international research collaboration is positively associated with team productivity. Using a bandwidth of 0.01 levels, collaborating teams perform much better than non collaborating teams of similar characteristics both in terms of their productive capacity and in terms of their probability of collaborating internationally. Collaborating internationally increases expected output by 4 bibliographic products.

TABLE 2

Co-Authorship AND TeAm OutPut -Psm

\begin{tabular}{|c|c|c|c|c|c|c|}
\hline \multirow[b]{2}{*}{$\begin{array}{c}\text { Treatm } \\
\text { ent } \\
\text { bwidth } \\
: 0.01\end{array}$} & \multicolumn{6}{|c|}{ Team Productivity } \\
\hline & $\begin{array}{c}\text { Differe } \\
\text { nce } \\
\text { Unmat } \\
\text { ched }\end{array}$ & $\begin{array}{l}\mathrm{T}- \\
\text { stati } \\
\text { stic }\end{array}$ & $\begin{array}{c}\text { Differ } \\
\text { ence } \\
\text { Match } \\
\text { ed } \\
\text { ATE }\end{array}$ & $\begin{array}{c}\text { Differ } \\
\text { ence } \\
\text { Match } \\
\text { ed } \\
\text { ATT }\end{array}$ & $\begin{array}{l}\mathrm{T}- \\
\text { stati } \\
\text { stic }\end{array}$ & $\begin{array}{l}\text { On } \\
\text { Sup } \\
\text { port }\end{array}$ \\
\hline $\begin{array}{l}\text { Co- } \\
\text { Author } \\
\text { ship }\end{array}$ & 8.97 & 7.45 & 2.51 & 4.20 & 2.29 & 629 \\
\hline
\end{tabular}

Regarding the effects of international collaboration on the orientation of local research agendas in Colombia, and more precisely on the team's ability to contribute to local knowledge by the extent to which it uses the word "Colombi*" in the title or abstract of a journal article published by at least one of its members between 2003 and 2005, we find that, holding the other variables constant, team's odds of involving Colombia in its research process are 2.2 times larger for those co-authoring with a partner located overseas than for those working individually or in collaboration with local partners. This finding is statistically significant at the 0.01 level (see Table 3 ).

TABLE 3

Co-Authorship with Colleagues Located Overseas and Team Contribution to Local KNOWLEDGE

\begin{tabular}{lcccccc}
$\begin{array}{l}\text { Colombia' in } \\
\text { Prod or Proj }\end{array}$ & $\mathrm{b}$ & $\mathrm{z}$ & $\mathrm{P}>\mathrm{z}$ & $\%$ & $\%$ StdX & SDofX \\
\hline $\begin{array}{l}\text { Co- } \\
\text { Authorship in } \\
2001-2\end{array}$ & & & & & & \\
\hline
\end{tabular}

Moreover, holding all other variables constant at their means, co-authoring with partners located in other countries increases team probability of contributing to local knowledge by $9 \%$.

\section{CONCLUSIONS AND POLICY IMPLICATIONS}

Based on the two approaches used, that is, the econometric regressions and the non-parametric model, we found that coauthoring with partners located overseas is positively associated with local team productive capacity. It raises team expected production count by between 3 and 5 bibliographic products (see table 4). This finding clearly supports the hypothesis stated based on the "complementarity" argument discussed earlier. It seems that the knowledge, experience and tools brought about by scientists and engineers located overseas complement those existing locally and increases overall Colombian teams productive capacity.

TABLE 4

Summary Table: International ReSEARch Collaboration and Team OUTPUT: ZINB AND PSM

\begin{tabular}{l|ccc|cccc}
\hline & \multicolumn{3}{|c|}{ ZINB } & \multicolumn{4}{c}{ PSM } \\
& $\%$ & Count & $\mathrm{P}>|\mathrm{z}|$ & 0.01 & T- & 0.05 & T- \\
& level & stat & level & stat \\
\hline Co-Authorship & 39 & 2.91 & 0.011 & 4.20 & 2.29 & 4.63 & 2.6 \\
\hline
\end{tabular}

In addition, we found that international co-authorship is also positively associated with team's ability to contribute to local knowledge. It raises team's expected probability by between $9 \%$ and $16 \%$ (see table 5). This finding rejects the pessimistic hypothesis supporting the "outsourcing" argument discussed. It seems that partners located overseas collaborate with local scientists and engineers to work mostly on Colombian issues or on issues where Colombia is of scientific interest. 
TABLE 5

Summary TABLE: InTERnATIONAL RESEARCH COLlaboration AND TEAM Contribution to LocAl KnOWLedGe: Logit AND PsM

\begin{tabular}{lrrr|rr}
\hline & \multicolumn{3}{c|}{ Logit } & \multicolumn{2}{c}{ PSM (\%) } \\
& $\% \mathrm{a}$ & $\% \mathrm{~b}$ & $\mathrm{P}>|\mathrm{z}|$ & 0.01 & T-stat \\
\hline Co- & 121.3 & 9.0 & 0.005 & 16.0 & 3.11 \\
\hline
\end{tabular}

$\%$ a: Percentage Change in Odds

$\%$ b: Changes in Predicted Probabilities for 'Colombia' in Products or Projects

These findings are revealing considering the fact that Colombian research teams are characteristically local and reticent to work with international partners. In fact, based on the data analyzed, less than $26 \%$ of the teams received foreign funding between 2003 and 2005; close to $20 \%$ of the teams hosted foreign researchers between 2003 and 2005; and less than $24 \%$ of the teams co-authored with partners located overseas between 2001 and 2002 [4]. Had the majority of the teams collaborated internationally, the local stock of knowledge would have, as measured in terms of products or processes, increased dramatically. Not doing so implies high opportunity costs.

Consistent with these findings, promoting international collaboration is a most to increase local knowledge and capabilities in developing countries. Ways of doing that include the promotion of research network creation and participation, fellowships for Colombians willing to study overseas as well as for engaging foreign scientists to work in Colombia, and the support to international research projects, among others.

\section{REFERENCES}

[1] Wagner, C.S., et al., Science and Technology Collaboration: Building Capacities in Developing Countries? 2001, Santa Monica, CA: RAND.

[2] OCyT, Indicadores de Ciencia y Tecnologia. Colombia 2008. 2009, Bogota, D.C. Colombia: Observatorio Colombiano de Ciencia y Tecnologia.

[3] RICYT, Indicadores de Ciencia y Tecnología actualizados al año 2007. 2009, Buenos Aires, Argentina: Red Iberoamericana de Indicadores de Ciencia y Tecnologia www.ricyt.edu.ar.

[4] Ordonez, G., International Research Collaboration, Research Team Performance, and Scientific and Technological Capabilities in Colombia -A Bottom-Up Perspective, in PhD Dissertation in Public Policy. Georgia Institute of Technology - Georgia State University. 2008: Atlanta, GA.

[5] Beaver, D.D., Does collaborative research have greater epistemic authority? Scientometrics, 2004. 60(3): p. 399-408.

[6] Wray, K.B., The epistemic significance of collaborative research. Philosophy of Science, 2002. 69(1): p. 150-168.

[7] Crane, D., Invisible Colleges: diffusion of knowledge in scientific communities. 1972, Chicago, IL: The University of Chicago Press.

[8] Beaver, D.D. and R. Rosen, Studies in Scientific Collaboration .2. Scientific Co-Authorship, Research Productivity and Visibility in the French Scientific Elite, 1799-1830. Scientometrics, 1979. 1(2): p. 133-149.

[9] Rigby, J. and J. Edler, Peering inside research networks: Some observations on the effect of the intensity of collaboration on the variability of research quality. Research Policy, 2005. 34(6): p. 784794.

[10] Farrell, M.P., Collaborative circles: friendship dynamics and creative work. 2001, Chicago: University of Chicago Press.

[11] Burt, R.S., Structural holes and good ideas. American Journal of Sociology, 2004. 110(2): p. 349-399.

[12] Levine, J.M. and R.L. Moreland, Collaboration: The social context of theory development. Personality and Social Psychology Review, 2004. 8(2): p. 164-172.

[13] Uzzi, B. and J. Spiro, Collaboration and creativity: The small world problem. American Journal of Sociology, 2005. 111(2): p. 447-504.

[14] Landry, R., N. Traore, and B. Godin, An econometric analysis of the effect of collaboration on academic research productivity. Higher Education, 1996. 32(3): p. 283-301.

[15] Adams, J.D., et al., Scientific teams and institutional collaborations: Evidence from US universities, 1981-1999. Research Policy, 2005. 34(3): p. 259-285.

[16] Lee, S. and B. Bozeman, The impact of research collaboration on scientific productivity. Social Studies of Science, 2005. 35(5): p. 673702 .

[17] Turner, L. and J. Mairesse, Individual Productivity Differences in Public Research: how important are non-individual determinants? An economic study of French physicists' publications and citations (1986-1997). 2005. p. Unpublished Manuscript. 35 p.

[18] Fox, M.F. and C.A. Faver, Independence and Cooperation in Research - the Motivations and Costs of Collaboration. Journal of Higher Education, 1984. 55(3): p. 347-359.

[19] Landry, R. and N. Amara, The impact of transaction costs on the institutional structuration of collaborative academic research. Research Policy, 1998. 27(9): p. 901-913.

[20] Carayol, N. and M. Matt, Does research organization influence academic production? Laboratory level evidence from a large European university. Research Policy, 2004b. 33(8): p. 1081-1102.

[21] Cummings, J.N. and S. Kiesler, Collaborative research across disciplinary and organizational boundaries. Social Studies of Science, 2005. 35(5): p. 703-722.

[22] Sagasti, F., Knowledge and Innovation for Development: The Sisyphus Challenge of the 21st Century. 2004, Northampton, MA.: Edward Elgar. 151.

[23] Kleinman, D., Pervasive Influence: Intellectual Property, Industrial History, and University Science. Science and Public Policy, 1998: p. 95-102.

[24] Florida, R., The Role of the University: Leveraging Talent, Not Technology. Issues in Science \& Technology, 1999(Summer).

[25] Shrum, W., Reagency of the Internet, or, how I became a guest for science. Social Studies of Science, 2005. 35(5): p. 723-754.

[26] Granovetter, M., The Strength of Weak Ties. The American Journal of Sociology, 1973. 78(6): p. 1380.

[27] Granovetter, M., The impact of social structure on economic outcomes. Journal of Economic Perspectives, 2005. 19(1): p. 33-50.

[28] Guan, J.C. and J.X. Wang, Evaluation and interpretation of knowledge production efficiency. Scientometrics, 2004. 59(1): p. 131155.

[29] Bonaccorsi, A. and C. Daraio, Exploring size and agglomeration effects on public research productivity. Scientometrics, 2005. 63(1): p. 87-120.

[30] Bonaccorsi, A., C. Daraio, and L. Simar, Advanced indicators of productivity of universities. An application of robust nonparametric methods to Italian data. Scientometrics, 2006. 66(2): p. 389-410.

[31] Bordons, M., et al., Local, domestic and international scientific collaboration in biomedical research. Scientometrics, 1996. 37(2): $\mathrm{p}$. 279-295.

[32] Bordons, M. and M.A. Zulueta, Comparison of research team activity in two biomedical fields. Scientometrics, 1997. 40(3): p. 423-436.

[33] Bordons, M., M.A. Zulueta, and S. Barrigon, Scientific activity of the most productive Spanish research teams in pharmacology and pharmacy during the period 1986-1993 as covered by the Science Citation Index (SCI). Medicina Clinica, 1998. 111(13): p. 489-495.

[34] Cohen, J.E., Publication Rate as a Function of Laboratory Size in a Biomedical-Research Institution. Scientometrics, 1980. 2(1): p. 3552. 
[35] Cohen, J.E., Publication Rate as a Function of Laboratory Size in 3 Biomedical-Research Institutions. Scientometrics, 1981. 3(6): p. 467487.

[36] Cohen, J.E., Size, Age and Productivity of Scientific and Technical Research Groups. Scientometrics, 1991. 20(3): p. 395-416.

[37] Kretschmer, H., Cooperation Structure, Group-Size and Productivity in Research Groups. Scientometrics, 1985. 7(1-2): p. 39-53.

[38] Kyvik, S., Are Big University Departments Better Than Small Ones. Higher Education, 1995. 30(3): p. 295-304.

[39] Lima, M., S. Liberman, and J.M. Russell, Scientific group cohesiveness at the National University of Mexico. Scientometrics, 2005. 64(1): p. 55-66.

[40] Martin-Sempere, M.J., J. Rey-Rocha, and B. Garzon-Garcia, The effect of team consolidation on research collaboration and performance of scientists. Case study of Spanish university researchers in Geology. Scientometrics, 2002. 55(3): p. 377-394.

[41] Noltingk, B.E., A Note on Effective Laboratory Size. R \& D Management, 1985. 15(1): p. 65-69.

[42] Qurashi, M.M., Publication Rate as a Function of the Laboratory Group-Size. Scientometrics, 1984. 6(1): p. 19-26.

[43] Qurashi, M.M., Publication-Rate and Size of Two Prolific Research Groups in Departments of Inorganic-Chemistry at Dacca University (1944-1965) and Zoology at Karachi University (1966-84). Scientometrics, 1991. 20(1): p. 79-92.

[44] Qurashi, M.M., Dependence of Publication-Rate on Size of Some University Groups and Departments in Uk and Greece in Comparison with Nci, USA. Scientometrics, 1993. 27(1): p. 19-38.

[45] Rey-Rocha, J., M.J. Martin-Sempere, and B. Garzon, Research productivity of scientists in consolidated vs. non-consolidated teams: The case of Spanish university geologists. Scientometrics, 2002. 55(1): p. 137-156.

[46] Seglen, P.O. and D.W. Aksnes, Scientific productivity and group size: A bibliometric analysis of Norwegian microbiological research. Scientometrics, 2000. 49(1): p. 125-143.

[47] Stankiewicz, R., The size and age of Swedish academic research groups and their scientific performance, in Scientific Productivity: the effectiveness of research groups in six countries, F.M. Andrews, Editor. 1979, Cambridge University Press and UNESCO: Paris. p. 191-222.

[48] Wang, J.X. and J.C. Guan, The analysis and evaluation of knowledge efficiency in research groups. Journal of the American Society for Information Science and Technology, 2005. 56(11): p. 1217-1226.

[49] Harrison, D.A., et al., Time, teams, and task performance: Changing effects of surface- and deep-level diversity on group functioning. Academy of Management Journal, 2002. 45(5): p. 1029-1045.

[50] Smeby, J.C. and S. Try, Departmental contexts and faculty research activity in Norway. Research in Higher Education, 2005. 46(6): p. 593-619.

[51] Ettorre, E., Recognizing diversity and group processes in international, collaborative research work: A case study. Social Policy \& Administration, 2000. 34(4): p. 392-407.

[52] Porac, J.F., et al., Human capital heterogeneity, collaborative relationships, and publication patterns in a multidisciplinary scientific alliance: a comparative case study of two scientific teams. Research Policy, 2004. 33(4): p. 661-678.

[53] Danilovic, M. and W. Mats, A tentative framework for analyzing integration in collaborative manufacturing network settings: a case study. Journal of Engineering and Technology Management, 2005. 22(1-2): p. 141-158.

[54] Waguespack, D.M. and J.K. Birnir, Foreignness and the diffusion of ideas. Journal of Engineering and Technology Management, 2005. 22(1-2): p. 31-50.

[55] Melin, G., Postdoc abroad: inherited scientific contacts or establishment of new networks? Research Evaluation, 2004. 13(2): p. 95-102.

[56] Dietz, J., Scientists and Engineers in Academic Research Centers -An examination of career patterns and productivity. PhD Thesis, in School of Public Policy. 2004, Georgia Institute of Technology: Atlanta, GA. p. 186.

[57] Moed, H.F., Bibliometric indicators reflect publication and management strategies. Scientometrics, 2000. 47(2): p. 323-346.
[58] Frederiksen, L.F., Disciplinary determinants of bibliometric impact in Danish industrial research: Collaboration and visibility. Scientometrics, 2004. 61(2): p. 253-270.

[59] Qin, J., F.W. Lancaster, and B. Allen, Types and levels of collaboration in interdisciplinary research in the sciences. Journal of the American Society for Information Science, 1997. 48(10): p. 893916.

[60] Bauer, H.H., Barriers against Interdisciplinarity - Implications for Studies of Science, Technology, and Society (Sts). Science Technology \& Human Values, 1990. 15(1): p. 105-119.

[61] Becher, T., The Significance of Disciplinary Differences. Studies in Higher Education, 1994. 19(2): p. 151-161.

[62] Becher, T., Towards a Definition of Disciplinary Cultures. Studies in Higher Education, 1981. 6(2): p. 109-122.

[63] Frame, J.D. and M.P. Carpenter, International Research Collaboration. Social Studies of Science, 1979. 9(4): p. 481-497.

[64] Wagner, C.S., Six case studies of international collaboration in science. Scientometrics, 2005. 62(1): p. 3-26.

[65] Whitley, R., The intellectual and social organization of the sciences. 2000, Oxford, UK: Oxford University Press.

[66] Rinia, E.J., T.N. Van Leeuwen, and A.F.J. Van Raan, Impact measures of interdisciplinary research in physics. Scientometrics, 2002. 53(2): p. 241-248.

[67] Okubo, Y., et al., A multivariate analysis of publication trends in the 1980s with special reference to south-east Asia. Scientometrics, 1998. 41(3): p. 273-289.

[68] Schummer, J., Multidisciplinarity, interdisciplinarity, and patterns of research collaboration in nanoscience and nanotechnology. Scientometrics, 2004. 59(3): p. 425-465.

[69] Godin, B. and Y. Gingras, Impact of collaborative research on academic science. Science and Public Policy, 2000. 27(1): p. 9.

[70] Etzkowitz, H. and L. Leydesdorff, The dynamics of innovation: from National Systems and "Mode 2" to a Triple Helix of universityindustry-government relations. Research Policy, 2000. 29(2): p. 109123.

[71] Hagedoorn, J., Inter-firm R\&D partnerships: an overview of major trends and patterns since 1960. Research Policy, 2002. 31(4): p. 477492.

[72] Frenken, K., W. Hölzl, and F. de Vor, The citation impact of research collaborations: the case of European biotechnology and applied microbiology (1988-2002). Journal of Engineering and Technology Management, 2005. 22(1-2): p. 9-30.

[73] Acs, Z., J. de la Mothe, and G. Paquet, Local Systems of Innovation: In Search of an Enabling Strategy, in The Implications of KnowledgeBased Growth for Micro-Economic Policies, P. Howitt, Editor. 1996, University of Calgary Press: Calgary. p. 339-358.

[74] Casper, S. and A. Karamanos, Commercializing science in Europe: The Cambridge biotechnology cluster. European Planning Studies, 2003. 11(7): p. 805-822.

[75] Liang, L.M. and L. Zhu, Major factors affecting China's interregional research collaboration: Regional scientific productivity and geographical proximity. Scientometrics, 2002. 55(2): p. 287-316.

[76] Malo, S. and A. Geuna, Science-technology linkages in an emerging research platform: The case of combinatorial chemistry and biology. Scientometrics, 2000. 47(2): p. 303-321.

[77] McKelvey, M., H. Alm, and M. Riccaboni, Does co-location matter for formal knowledge collaboration in the Swedish biotechnologypharmaceutical sector? Research Policy, 2003. 32(3): p. 483-501.

[78] Stolpe, M., Determinants of knowledge diffusion as evidenced in patent data: the case of liquid crystal display technology. Research Policy, 2002. 31(7): p. 1181-1198.

[79] Zitt, M., et al., Potential science-technology spillovers in regions: An insight on geographic co-location of knowledge activities in the EU. Scientometrics, 2003. 57(2): p. 295-320.

[80] Saxenian, A., Regional Advantage, Culture and Competition in Silicon Valley and Route 128. 1994, Cambridge, MA.: Harvard University Press.

[81] Scott, A.J., ed. Global City-Regions. 2001, Oxford University Press.: Oxford.

[82] Hoegl, M. and L. Proserpio, Team member proximity and teamwork in innovative projects. Research Policy, 2004. 33(8): p. 1153-1165. 
[83] Georghiou, L., Global cooperation in research. Research Policy, 1998. 27(6): p. 611-626.

[84] Georghiou, L., Evolving frameworks for European collaboration in research and technology. Research Policy, 2001. 30(6): p. 891-903.

[85] Smeby, J.C. and J. Trondal, Globalisation or europeanisation? International contact among university staff. Higher Education, 2005. 49(4): p. 449-466.

[86] Long, J.S. and J. Freese, Regression Models for Categorical Dependent Variables Using Stata. 2001, College Station, Texas: Stata Corporation.

[87] Lewis, G., Dichotomous Dependent Variables, in Lecture Notes 01. PAUS 9121. Advance Research Methods II. 2003: Georgia State University. Atlanta, GA.

[88] Caliendo, M. and S. Kopeining, Some Practical Guidance for Implementation of Propensity Score Matching. Journal of Economic Surveys, 2008. 22(1): p. 31-72.

[89] Rosenbaum, P.R. and D.B. Rubin, The Central Role of the Propensity Score in Observational Studies for Causal Effects. Biometrika, 1983. 70(1): p. 41-55.

[90] Zhao, Z., Using Matching to Estimate Treatment Effects: Data Requirements, Matching Metrics, and Monte Carlo Evidence. The Review of Economics and Statistics, 2004. 80(1): p. 91-107.

[91] Leuven, E. and B. Sianesi, PSMATCH2: Stata module to perform full Mahalanobis and propensity score matching, common support graphing, and covariate imbalance testing. 2003, Boston College Department of Economics. 